\title{
Polycistronic expression of CGA-N46 gene in Bacillus subtilis DB1342
}

\author{
Rui-fang Li, Bin Wang, Yan-jie Yi, Liang Huang, and Qian-cheng Xiong \\ College of Bioengineering, Henan University of Technology, Zhengzhou 450001, China.
}

Accepted 20 December, 2012

\begin{abstract}
CGA-N46 is a small antifungal derived peptide and consists of the 31st to 76th amino acids of the Nterminus of human Chromogranin A. Polycistronic expression of CGA-N46 gene in Bacillus subtilis DB1342 was used to improve its production. Single, double and three copies of exogenous gene fragment which contained ribosome binding site (RBS), sacB signal peptide nucleotide sequence (sacB s), CGA-N46 encoding sequence (cga-N46) and stop codon were tandem constructed into the muticloning sites of PSBPTQ. The engineered expression plasmids which bore monocistronic, bicistronic and tricistronic expression cassettes of the CGA-N46 gene were transformed into the competent $B$. subtilis strain DB1342. The expression results of the engineered strains DB1342(p-N46), DB1342(p-2N46) and DB1342(p-3N46) demonstrated that monocistronic and bicistronic expression systems produced low amounts of CGA-N46 while the tricistronic expression system improved the production of the peptide. Our results are helpful for improving the production of small peptides by engineered strains.
\end{abstract}

Key words: Antifungal peptide, CGA-N46, Polycistronic expression, Secreted expression.

\section{INTRODUCTION}

Nosocomial bloodstream fungal infection remains a serious problem amongst hospitalized patients. Candidaemia is reported to be a major cause of morbidity and mortality (Ortega et al., 2011). The mortality of invasive Candida is unacceptably high and approaches 40\% (Wisplinghoff et al., 2004; Gudlaugsson et al., 2003; Diekema et al., 2003). Azoles drugs are commonly used to treat infections caused by $C$. albican. However, there has been considerable evidence, which has proved that these medicines are becoming ineffective. The reasons for this are the appearance of drug resistance of candida strains and side effects of azoles in some individuals. On the contrary, peptide resistance is uncommon (Foubister, 2003).

Chromogranin A (CGA) is a ubiquitous secreted protein by most endocrine cells and it is present at nanomolar concentration in the human vascular system. In recent studies, some properties of the CGA N-domain have been described. Vasostatin-I (CGA1-76), which is the natural fragment of chromogranin $\mathrm{A}$, is able to kill a large variety of fungi and yeast cells in micromolar range (Lugardon et al., 2000). CGA-N46, which is a derived peptide containing the 31st to 76th amino acid of the $\mathrm{N}$ terminus of CGA, has special antagonistic activities to $C$. albican (Li et al., 2006). However, the mechanism has not been established yet, which hampers its application in drug exploration. With a study about the CGA-N terminus fragment, Lugardon and colleagues proposed that the destabilization of fungal cell wall and plasma membrane, together with intracellular inhibition of calmodulindependent enzymes, might be the reason by which vasostatin-I and chromofungin could inhibit the growth of fungi (Lugardon et al., 2001). Another related study suggested that vasostatin-I and CGA47-66 at concentrations of $5-10 \mathrm{nmol} / /$ might engage in electrostatic as well as hydrophobic interactions with membrane-relevant phospholipids at physiological conditions. In particular, vasostatin-I enhanced the fluidity of saturated species 
of phosphatidylserine (Blois et al., 2006). Both of these mechanisms differ distinctly from each other. Therefore, these conclusions appear not to be solid and may need to be investigated further. To gain a deeper understanding of the antifungal mechanism of CGA-N46 and the need of drug development for future clinical application, a wealthy availability of CGA-N46 appears to be necessary. In addition, gene engineering is needed for its mass production.

Gene engineering approach is an effective means for large-scale production of peptides in vitro. In the last decade, many small peptides have been produced successfully using recombinant DNA technology. The most commonly used host cell is $E$. coli because of its fast growth and well-established expression system. However, expression of small peptides using $E$. coli as the host cell has been hampered by some barriers: (1) the formation of inclusion makes the isolation and purification of peptides difficult; (2) the susceptibility to proteolytic degradation (Zhong et al., 2006).

Fusion expression could overcome proteolytic degradation at certain level; however, it needs expensive and special cleavage enzyme to get the target protein. Construction of expression plasmids to express tandem repeat peptides is another approach to solve the above problems (Lee et al., 2002; Lennick et al., 1987) but products' multimerization may affect their native properties.

The polycistronic expression method is usually used to express a protein complex (Tan et al., 2005; Hierro et al., 2005; Shim et al., 2012). Construction of a polycistronic expression plasmid to express multiple copies of the expression cassette of one single exogenous gene in one plasmid may be one of the effective approaches to overcome the above barriers. Here, the expression of one single gene, namely cga-N46, via a polycistronic strategy in order to increase its expression level is described.

\section{MATERIALS AND METHODS}

\section{Plasmids and strains}

The plasmid pSBPTQ, an E. coli-B.subtilis shuttle plasmid, was used to construct a recombinant expression plasmid in $B$. subtilis. It has the strong sacBpromoter of $B$. subtilis $\operatorname{sacB} p$, which is a sucrose-inducible promoter. The pSC31-76 plasmid was used as the template of the CGA-N46 gene. Plasmid amplification, subcloning experiment and related gene manipulation were performed in $E$. coli DH5a. A four-protease-deficient $B$. subtilis strain DB1342 (his nprR2 nprE18 aprAS epr) was used for all the protein expression experiments. The plasmid pMD18-T was purchased from Takara Bio. Inc (Dalian, China).

\section{Primers synthesis and PCR amplification}

Four primers, namely $\mathrm{P} 1, \mathrm{P} 2, \mathrm{P} 3$ and $\mathrm{P} 4$, were designed. $\mathrm{P} 1: 5^{\prime}$ ccc atg cct gtc agc aag $3^{\prime}$, P2: $5^{\prime}$ gct agc tta ctg ctg atg tgc cct ctc $3^{\prime}$ (The Nhel site is underlined), P3: 5' gct agc ccg cta aca cag ta ata
3' (The Nhel site is underlined) and P4: 5' ggt acc actagt tta ctg ctg atg tgc cct ctc $3^{\prime}$ (The Kpnl and Spel sites are underlined respectively from $5^{\prime}$ terminus to $3^{\prime}$ terminus). All the primers were synthesized by Shanghai Sangon Inc (Shanghai, China).

There is a SacB signal peptide nucleotide sequence ( $\operatorname{sac} B s$ ) downstream of the SacB $p$ in the pSBPTQ plasmid, a secreted expression vector of $B$. subtilis. There was no start codon (ATG) in primer P1. Primer P3 was designed according to the sequence of RBS of SacB. To make sure the stop of translation at desired position, the antisense stop codon TTA was added in primers P2 and P4.

To facilitate genetic manipulation and simplify the construction of polycistronic plasmids, pMD18-T was an intermediate vector for genetic cloning. There are Xbal (431 bp) and Kpnl (450 bp) restriction sites in pMD18-T, but they are not at the flanks of the $T$ cloning site (425 bp). To subclone the exogenous gene, which was cloned in the T site of pMD18-T, into pSBPTQ between Xbal and Kpnl, a $K p n l$ restriction site had to be added in the $5^{\prime}$ terminus of primer P4.

Fragments cga-N46, cga-N46-Kpnl, and SacB s-cga-N46 were obtained by polymerase chain reaction (PCR) amplification of the pSC31-76 plasmid. The oligonucleotide primers $\mathrm{P} 1$ and $\mathrm{P} 2$ were used for amplifying cga-N46. The oligonucleotide primers P3 and P4 were used for amplifying sacBs-cga-N46, which contains the RBS and sacB signal peptide sequences. To construct the monocistronic expression plasmid, cga-N46-Kpnl, which contains Kpnl at 3 ' terminus, was amplified using the oligonucleotide primers $\mathrm{P} 1$ and P4.

\section{Construction of recombinant $\mathrm{T}$ plasmids}

PCR products cga-N46, cga-N46-Kpnl and sacBs-cga-N46, which had A-terminus, were recombined with pMD18-T plasmids, which had T-terminus, using T4 DNA ligase. The recombinant plasmids were transformed into $E$. coli $\mathrm{DH} 5 \mathrm{a}$ and positive clones were screened by blue and white colony color. The target recombinant plasmids were identified by restriction endonuclease digestion.

\section{Construction of polycistronic cga-N46 cassettes into PSBPTQ}

Plasmid pSBPTQ had $s a c B$ promoter and signal peptide nucleotide sequence. The exogenous gene at the downstream of the signal peptide sequence of PSBPTQ could be expressed by $B$. subtilis. After digestion of the recombinant $T$ plasmids and PSBPTQ with $K p n l$ and Xbal, these two fragments were linked together by T4 DNA ligase. The positive recombinant plasmids were digested to verify the presence of cistronic cassettes. The target recombinant plasmids were transformed into $B$. subtilis DB1342 competent cells for protein expression. B. subtilis DB1342 competent cells were prepared by Spizizen method (Spizizen, 1958) and positive colonies could grow in LB agar containing $10 \mu \mathrm{g} / \mathrm{ml}$ kanamycin.

\section{Expression analysis of CGA-N46}

The seed culture was prepared by transferring a loop of engineered $B$. subtilis DB1342 cells from a fresh culture grown on LB agar into $25 \mathrm{ml}$ LB broth $(10 \mu \mathrm{g} / \mathrm{ml}$ kanamycin) in a $250 \mathrm{ml}$ Erlenmeyer flask. The flask was incubated in a shaker $(230 \mathrm{rpm})$ at $37^{\circ} \mathrm{C}$ for $16 \mathrm{~h}$.

The expression process was carried out in Erlenmeyer flasks $(250 \mathrm{ml}$ ) containing $50 \mathrm{ml}$ aliquots of $2 \times \mathrm{MSR}$ (modified super rich medium, $5 \% \mathrm{w} / \mathrm{v}$ yeast extract, $3 \% \mathrm{w} / \mathrm{v}$ peptone, $0.6 \% \mathrm{w} / \mathrm{v} \mathrm{K}_{2} \mathrm{HPO}_{4}$ and $0.6 \% \mathrm{w} / \mathrm{v}$ glucose) supplemented with $10 \mu \mathrm{g} / \mathrm{ml}$ kanamycin The flasks were inoculated with the seed culture at $5 \% \mathrm{v} / \mathrm{v}$ and incubated in a shaking incubator (230 rpm). Protein expression was induced after culturing for $3 \mathrm{~h}$ by the addition of $2 \%$ sucrose. Culture samples were collected at $30 \mathrm{~h}$ after induction and were 


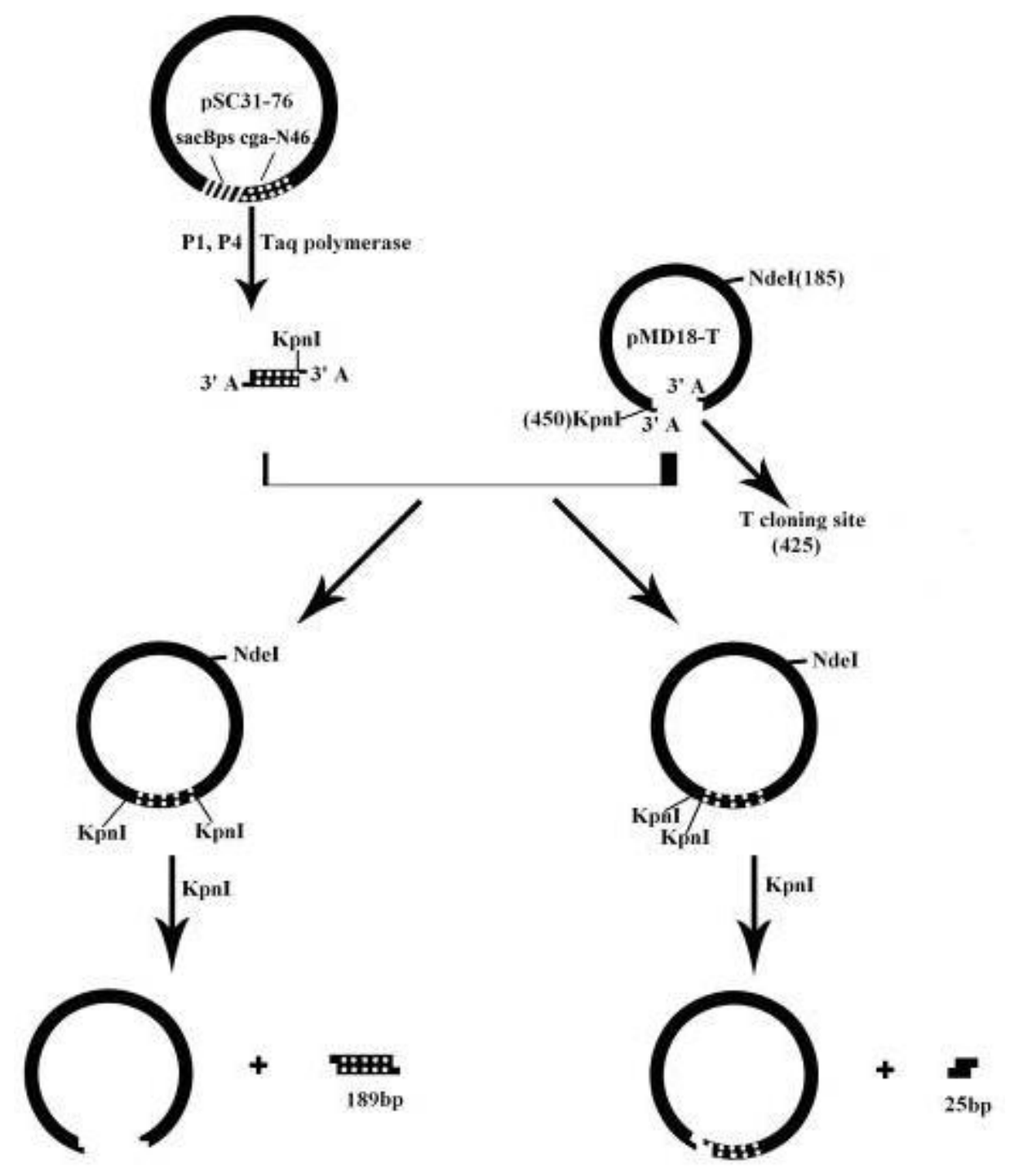

Figure 1. Construction and screening of the recombinant plasmid pT-N46-KpnI. Plasmid pSC31-76 was amplified using the oligonucleotide primers P1 and P4. The PCR fragment cga-N46-Kpnl was recombined with the pMD18-T plasmid using T4 DNA ligase. There were two Kpnl sites on the recombinant plasmids. One was at 450 bp site of pMD18-T and another one was at $3^{\prime}$ terminus of cga-N46-Kpnl, which was inserted in the T cloning site at $425 \mathrm{bp}$ of pMD18-T. The fragment length of cga-N46-Kpnl was $164 \mathrm{bp}$. When the recombinant plasmids were digested by $K p n l$, there were two possible results for the length of the fragments digested out of recombined plasmids: $25 \mathrm{bp}$ and $189 \mathrm{bp}$ due to the insert orientation of the cga-N46-Kpnl fragment.

centrifuged at $10,000 \mathrm{xg}$ for 20 min before the fermentation supernatant was obtained. The production yield of CGA-N46 in the fermentation supernatant was analyzed by $16.5 \%$ SDS-PAGE.

\section{Assay of antifungal activity}

Antifungal activity of the filtered sucrose-induced culture broth of $B$. subtilis DB1342(p-3N46) was examined by well diffusion assays. One hundred microliter of $C$. albican suspension (approximately $10^{5}$ $\mathrm{cfu} / \mathrm{ml}$ ) was spread onto potato dextrose agar plates. The plates were then aseptically punched with $6-\mathrm{mm}$ holes in the agar using a cork borer and $100 \mu \mathrm{l} 0.22 \mu \mathrm{m}$-filtered culture broth of $B$. subtilis DB1342 ( $p-3 N 46)$ was added to the wells. For each tested plate, one well was filled with the filtered culture broth of $B$. subtilis DB1342(pSBPTQ) and the filtered sucrose-induced culture broth of B. subtilis DB1342(p-N46) served as control. The plates were left undisturbed to allow the solvent to diffuse into the agar and then incubated at $28^{\circ} \mathrm{C}$ overnight. Another $100 \mu \mathrm{l}$ of filtered culture broth was added until the total culture time was $36 \mathrm{~h}$. Diameters of growth inhibition zone were measured in millimeters (Aslam et al., 2011). The experiment was carried out in triplicate and the average value was recorded. 


\section{RESULTS}

\section{Construction and screening of recombinant plasmid pT -N46-Kpnl}

PCR fragments of cga-N46-Kpnl were recombined with pMD18-T plasmids. The target recombinant plasmids were screened by restriction endonuclease Kpnl digestion. Because there was one Kpnl digestion site on pMD18-T and a second one was introduced via cga-N46$K p n l$, two Kpnl digestion sites were present on the recombinant plasmids. The Kpnl on pMD18-T was at 450 bp site, the T cloning site was at $425 \mathrm{bp}$ of pMD18-T and the fragment length of cga-N46-Kpnl was $164 \mathrm{bp}$. Therefore, when the recombinant plasmids from cga-N46-Kpnl and PMD18-T were digested by Kpnl, there were two possible results for the fragment length of the digested recombinant plasmids: 25 bp or $189 \mathrm{bp}$ due to the insert orientation of the fragment cga-N46-Kpnl. The plasmids with $189 \mathrm{bp}$ fragment were the target recombinant plasmids (Figure 1) and named as pT-N46-Kpnl.

\section{Construction and screening of recombinant plasmid pT-N46}

PCR fragments of cga-N46 were recombined with pMD18-T plasmids. To test whether the fragment cgaN46 was inserted into pMD18-T, the recombinant plasmids were screened by double restriction digestion using Ndel and Nhel endonucleases. Results showed that there were two kinds of fragments digested out of the recombinant plasmids because of the orientation of the inserted fragment cga-N46. Because the T cloning site was at 425 $\mathrm{bp}$ of pMD18-T, the lengths of the fragments digested out of recombinant plasmids were calculated to be $240 \mathrm{bp}$ and $398 \mathrm{bp}$. The recombinant plasmids out of which the length of a $240 \mathrm{bp}$ fragment could be digested were the target plasmids (Figure 2) and named as pT-N46.

\section{Construction and screening of recombinant plasmid pT-SN46}

Fragments of sacBs-cga-N46 were recombined with pMD18-T plasmids. In order to check if the fragment of sacBs-cga-N46 was inserted into pMD18-T and screen the target recombinant plasmids, double restriction endonucleases Ndel and Nhel digestion were used. There were two kinds of fragments digested out of the recombinant plasmids because of the orientation of the inserted fragment sacBs-cga-N46. The fragment lengths digested out of recombinant plasmids were calculated to be 240 $\mathrm{bp}$ and $540 \mathrm{bp}$. The recombinant plasmids out of which could be digested out a 240 bp fragment were the target plasmids (Figure 3 ) and named as PT-SN46.

\section{Construction and screening of recombinant plasmid pT-2N46}

To construct the recombinant plasmid containing double copies of cga-N46, plasmids pT-N46 and pT-SN46 were digested by Ndel and Nhel respectively. Fragments containing cga-N46 from pT-N46 and pT-SN46 were linked by T4 DNA ligase. The protocol of pT-2N46 construction is shown in Figure 4.

\section{Construction and screening of recombinant plasmid pT-3N46}

Plasmid pT-2N46 was digested by Ndel and Nhel and the fragment containing cga-N46 was recirculated. Plasmid pT-2N46 was also digested by Ndel and Spel and the fragment containing cga-N46 was recirculated. Two recirculated fragments were linked together by T4 DNA ligase. The positive plasmids were named as pT-3N46. The progress of construction is shown in Figure 5.

\section{Construction of recombinant PSBPTQ plasmids}

There was a MCS including Kpnl and Xbal downstream of the promoter and signal peptide of $s a c B$ in PSBPTQ. The fragments digested from pT-N46, pT-2N46 and pT3N46 with Kpnl and Xbal were linked with the fragments digested from PSBPTQ with the same two endonucleases by T4 DNA ligase. The recombinant plasmids containing monocistronic, bicistronic and tricistronic cassettes of cga-N46 were constructed (Figure 6). Each cistron could express one copy of CGA-N46.

Expression of monocistronic, bicistronic and tricistronic cassettes of cga-N46

To gain the soluble secreted peptide CGA-N46, the engineered $B$. subtilis DB1342 cells, which bored recombinant plasmids $p-\mathrm{N} 46, p-2 \mathrm{~N} 46$, and $p-3 \mathrm{~N} 46$ respectively, were cultured in $2 \times M S R$ medium containing $10 \mu \mathrm{g} / \mathrm{ml}$ kanamycin for $3 \mathrm{~h}$. CGA-N46 gene expression was then induced by the addition of $2 \%$ sucrose. Culture broth of each engineered strain was collected after $30 \mathrm{~h}$. The yields of CGA-N46 in culture broth were compared by $16.5 \%$ SDS-PAGE (Figure 7).

The results show that CGA-N46 was mainly expressed in DB1342 ( $p-3 N 46)$ and secreted into culture broth whereas a very limited amount of CGA-N46 was expressed in DB1342(p-N46) and DB1342(p-2N46).

\section{Antifungal activity}

The antifungal activity of the filtered sucrose-induced culture broth of $B$. subtilis DB1342(p-3N46) was tested. The average diameter of the clear zone in the well diffusion assay was about $20 \mathrm{~mm}$ while there was nearly 
Afr. J. Microbiol. Res.

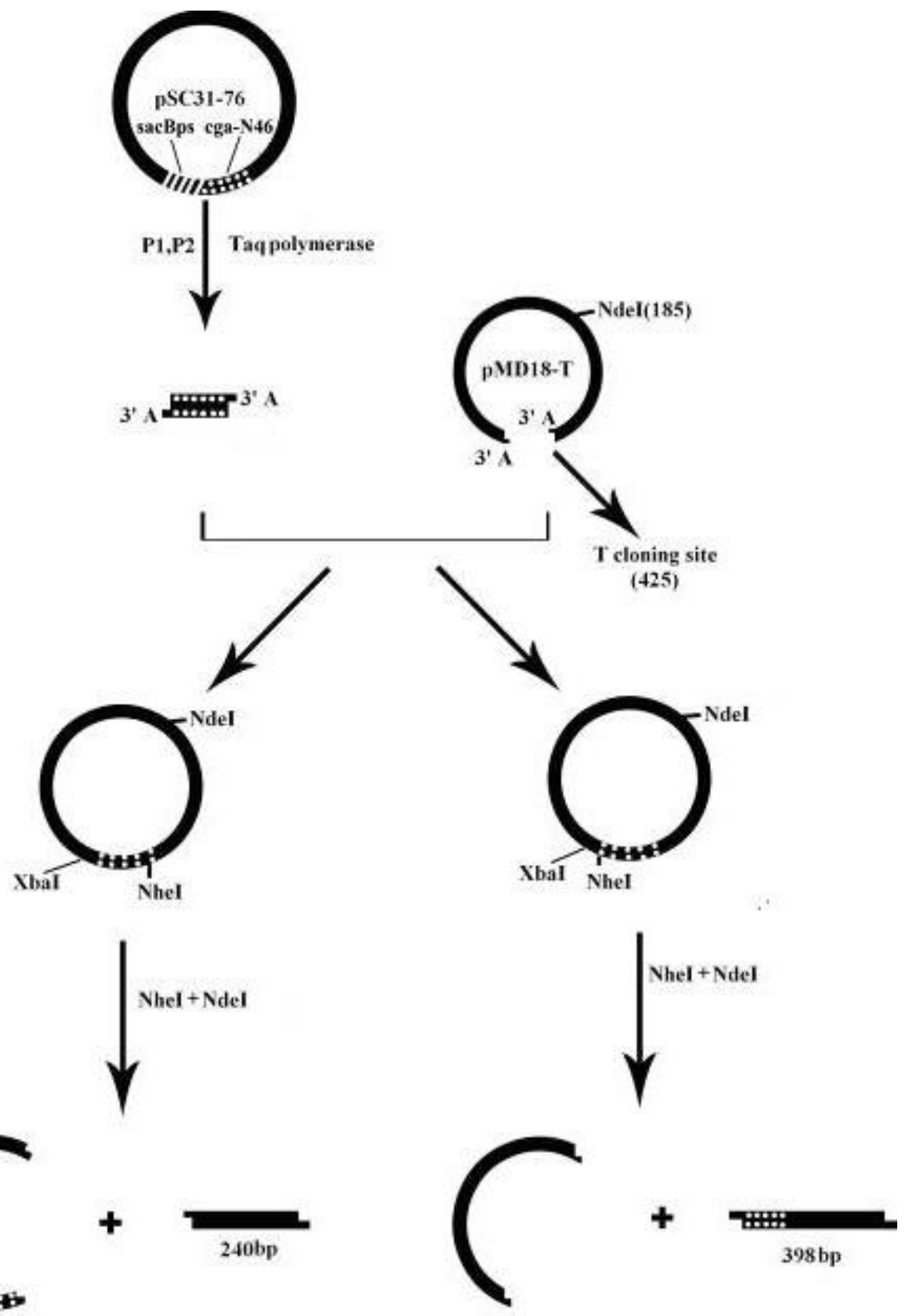

Figure 2. Construction and screening of the recombinant plasmid pT-N46. Plasmid pSC31-76 was amplified using the oligonucleotide primers P1 and P2. The PCR fragment cga-N46 was recombined with the pMD18-T plasmid using T4 DNA ligase. There were one Ndel site and one Nhel site on recombinant plasmids. The Ndel was at 185 bp site of pMD18-T, and Nhel was at the 3' terminus of cga-N46 which had been inserted in the T cloning site at $425 \mathrm{bp}$ of pMD18-T. The fragment length of cga-N46 was $158 \mathrm{bp}$. When the recombinant plasmids were digested by $\mathrm{Ndel}$ and $\mathrm{Nhel}$, there were two possible results for the length of the fragments digested out of the recombined plasmids: $240 \mathrm{bp}$ and $398 \mathrm{bp}$ due to the insert orientation of the cga-N46 fragment. 


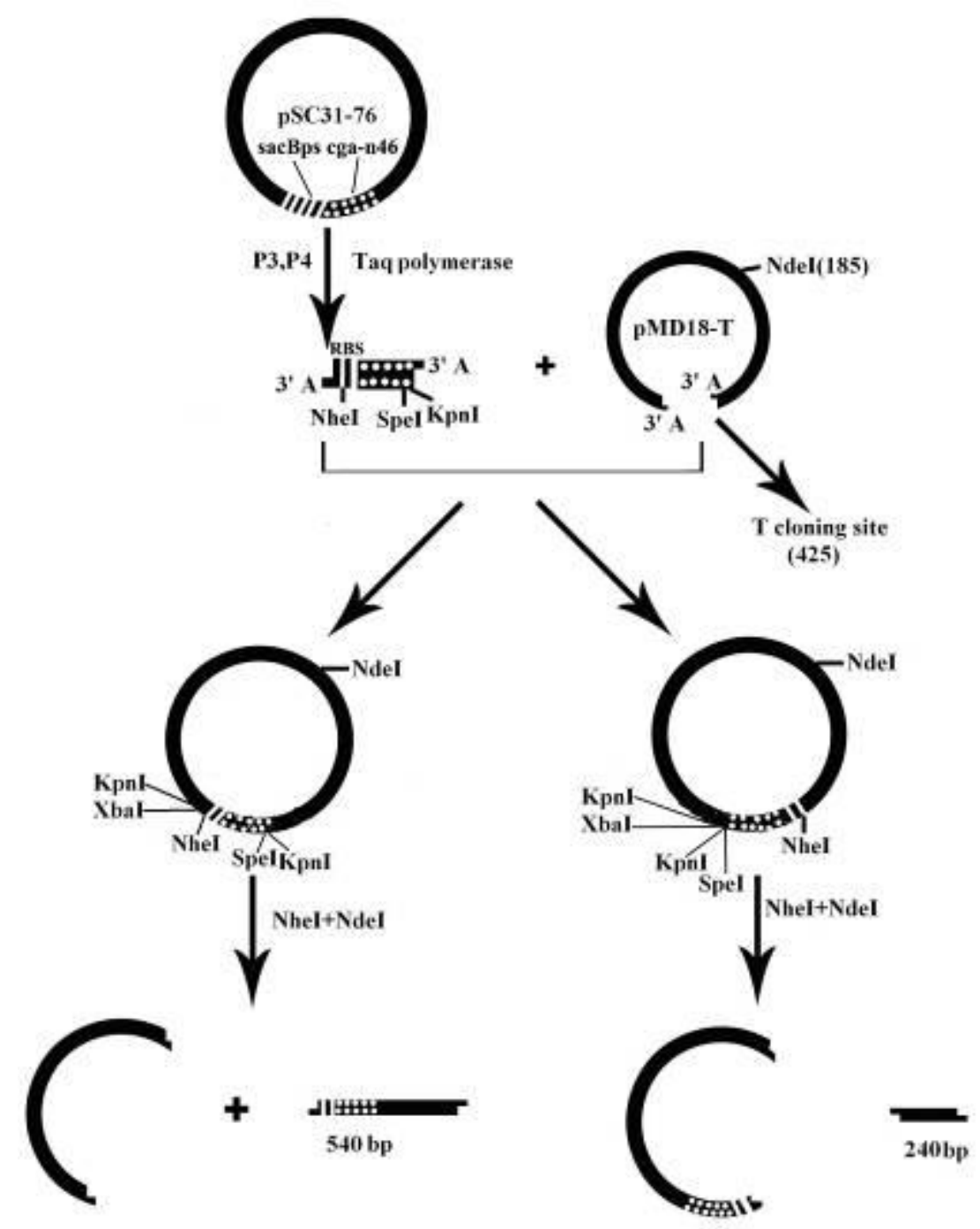

Figure 3. Construction and screening of the recombinant plasmid pT-SN46. Plasmid pSC31-76 was amplified using the oligonucleotide primers P3 and P4. The PCR product sacBs-cga-N46 was recombined with the pMD18-T plasmid using T4 DNA ligase. There were one Ndel site and one Nhel site on the recombinant plasmids. The Ndel was at $185 \mathrm{bp}$ site of pMD18-T and Nhel was at the 3' terminus of the sacBs-cga-N46 fragment, which had been inserted in the T cloning site at $425 \mathrm{bp}$ of pMD18-T. The fragment length of sacBs-cga-N46 was $300 \mathrm{bp}$. When the recombinant plasmids were digested by Ndel and Nhel, there were two possible results for the length of the fragment digested out of the recombined plasmids: $240 \mathrm{bp}$ and $540 \mathrm{bp}$ due to the insert orientation of the sacBs-cga-N46 fragment.

no clear zone for B. subtilis DB1342(pSBPTQ) culture broth and a little clear zone of culture broth of $B$. subtilis DB1342(p-N46) (Figure 8).

\section{DISCUSSION}

In this study, we expressed the cga-N46 gene by a tricistronic expression method in $B$. subtilis to improve the production of CGA-N46.

The tricistronic expression plasmid was constructed by Yang and colleagues (2006) using conventional plasmid construction methods to express Echistatin. Three pairs of primers, six kinds of restriction endonucleases, three times of PCR amplification, three times of endonuclease digestion and ligation reactions were needed in the conventional plasmid construction methods. To overcome the shortage of the conventional construction methods, 


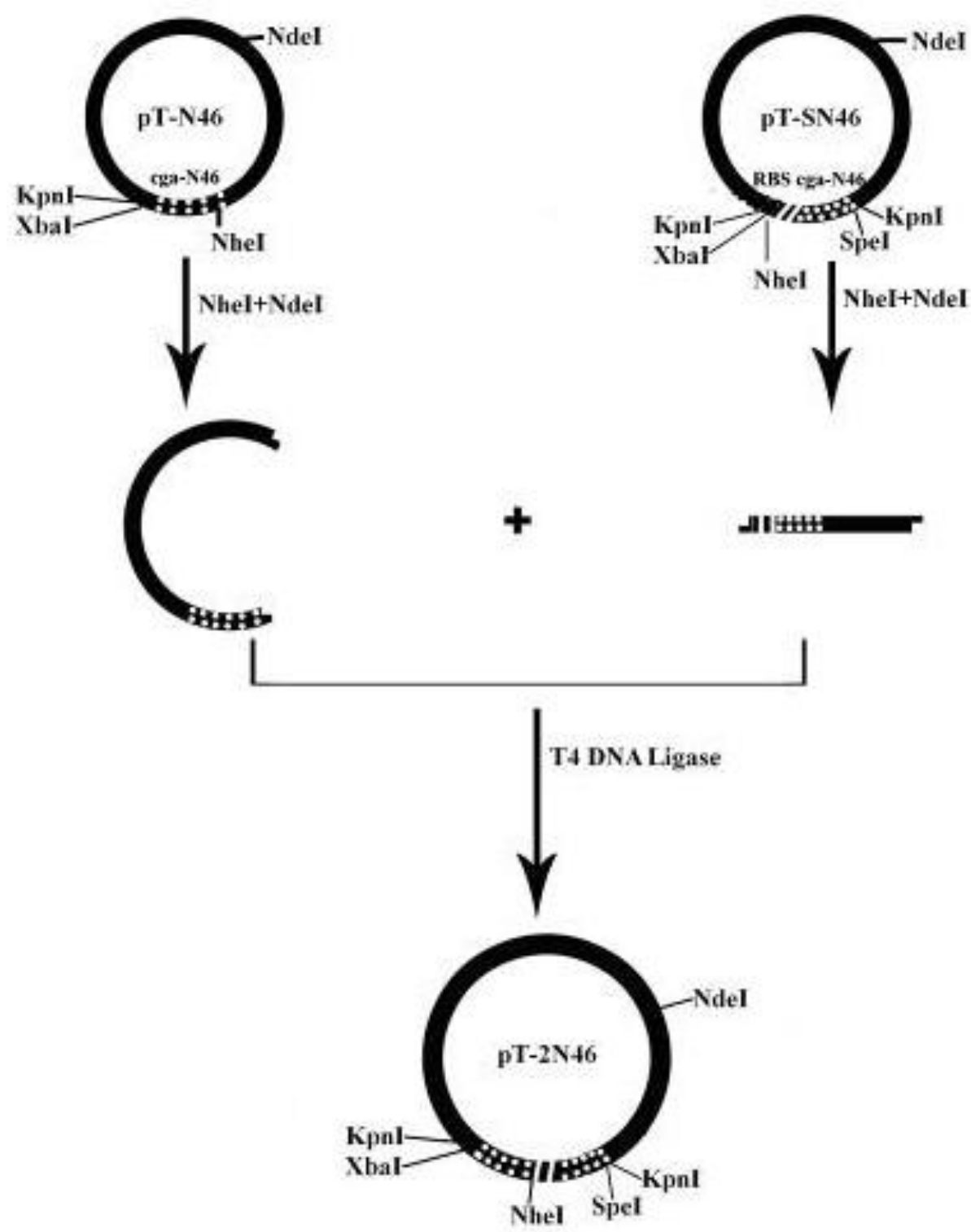

Figure 4. Construction of the recombinant plasmid pT-2N46. Plasmids pT-N46 and pTSN46 were digested by Ndel and Nhel respectively. The fragment from pT-N46 containing cga-N46 and the fragment from pT-SN46 containing sacBs-cga-N46 were recirculated and linked by T4 DNA ligase.

we investigated one simple and efficient method to construct a polycistronic expression plasmid in the study. Using a commercial T-plasmid as an intermediate plasmid, two pairs of primers were designed and Nhel and Spel restriction sites and RBS were introduced into the primers. DNA containing the target gene was used as a template for PCR amplification and the PCR products were linked with the T-plasmid. The derived recombinant T-plasmids were digested with Ndel plus Nhel and Ndel plus Spel, and the produced DNA fragments were linked by DNA ligase. Because Nhel and Spel have the same sticky end, their restriction sites disappeared after the sticky ends of the two fragments annealed. The copies of the single exogenous gene increased to $2 n-1$ ( $n$ was the number of the target gene in the recombinant T-plasmid constructed in the previous recombinant reaction, $n \geq 2$ ) via digestion and ligation as the above strategy. Finally, DNA fragments with multiple exogenous genes were subcloned into the expression plasmid at downstream of the promoter through the corresponding restriction digestion. Thus, the recombinant plasmids bearing a polycistronic expression cassette could be obtained.

Compared with the conventional plasmid construction technology, the construction method of polycistronic ex- 


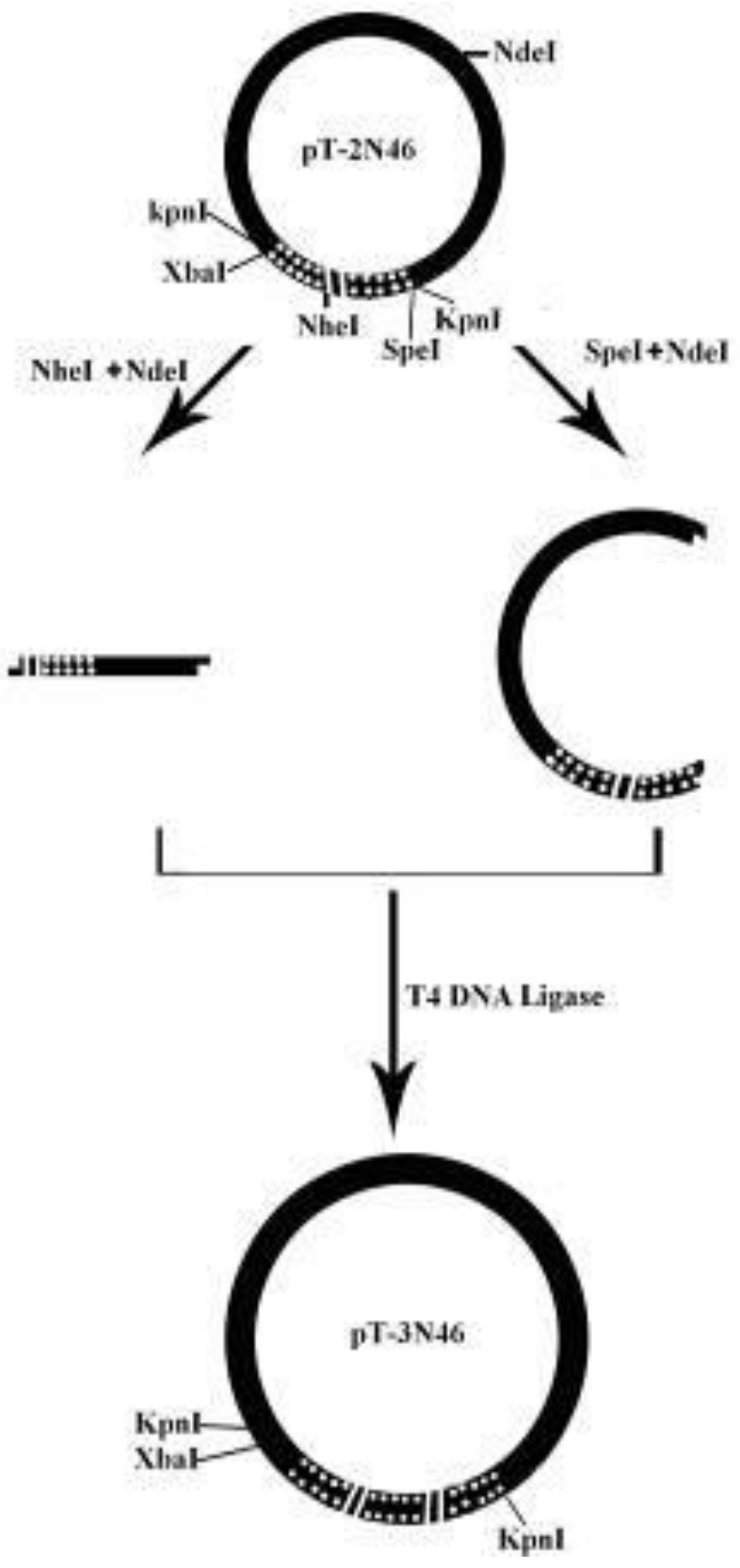

Figure 5. Construction of the recombinant plasmid pT-3N46. Plasmid pT-2N46 was digested by Ndel and Nhel and recirculated the sacBs-cga-N46 fragment. Plasmid pT-2N46 was digested by Ndel and Spel, and recirculated the cga-N46 fragment. Two recirculated fragments were linked together by T4 DNA ligase.

pression plasmid established in the present study has the following advantages: (1) Fewer kinds of restriction endonucleases are needed. $2 n$ ( $n$ stands for the number of cistrons) kinds of endonucleases are needed in the conventional plasmid construction technology. In contrast, no matter how many cistrons, only five kinds of endonucleases are needed in this method. (2) Fewer primers are needed. $\mathrm{n}$ ( $\mathrm{n}$ stands for the number of cistrons) pairs of primer are needed in the conventional plasmid construc- tion technology. On the contrary, only two pairs of primers are required regardless of how many cistrons are going to be recombined. (3) Fewer experimental steps. For example, if we construct a nine-cistronic expression plasmid using the conventional plasmid construction technology, 9 PCR reactions, 9 digestion and ligation reactions will be needed. However, only 2 PCR reactions, 5 digestion and ligation reactions are required by the method reported in this study. (4) The number of cistrons is unrestricted. The number of cistrons is limited by the number of restriction sites in the MCS of the expression plasmid in the conventional plasmid construction technology, whereas the number of cistrons is unrestricted in this method. Furthermore, this polycistronic plasmid construction method is simple and widely applicable. This method can be used to express all proteins, especially small peptides. On the other hand, the use of an intermediate plasmid in this method is not necessary. We can directly manipulate the exogenous gene in the expression plasmid and the resultant recombinant plasmids can be directly transformed into host cells, including both prokaryotic and eukaryotic cells.

Using the simple and efficient method established in this study, three kinds of polycistronic expression plasmids, namely p-N46, p-2N46 and p-3N46, were constructed. CGA-N46 was expressed and secreted from three engineered strains, namely DB1342(p-N46), DB1342(p$2 \mathrm{~N} 46)$ and DB1342(p-3N46). The results presented in Figure 7 demonstrated that the tricistronic expression cassette could express more target peptide than the monocistronic and bicistronic expression cassettes.

$B$. subtilis is not a pathogenic microbe and therefore it is harmless to human beings and livestock. $B$. subtilis also has a well-secretion system (Wong, 1995; Wu and Wong, 1999). Thus, it is an effective expression host. This is the reason why $B$. subtilis was used as expression host in this study. The expressing product was secreted into the medium to facilitate purification.

As expected, we increased the production and realized secreted expression of the antifungal peptide CGA-N46 by polycistronic expression in $B$. subtilis in this study. However, the yield of CGA-N46 in B. subtilis is still a practical limitation. Further research will be devoted to remove this limitation or chose another expression host. Nevertheless, we believe that the method established in this investigation may have wider application in such areas of protein expression in the future.

\section{ACKNOWLEDGEMENTS}

We are grateful to Dr. Li-xiang Cao and Professor Jinxian Luo (School of Life Sciences, Sun Yat-sen University, China) who made suggestions for improvements to this manuscript. We also thank Professor Jin-xian Luo for kindly providing the $B$. subtlis strain DB1342. This work was supported by the National Science Foundation of China (31071922), Science and Technology Plan Project 


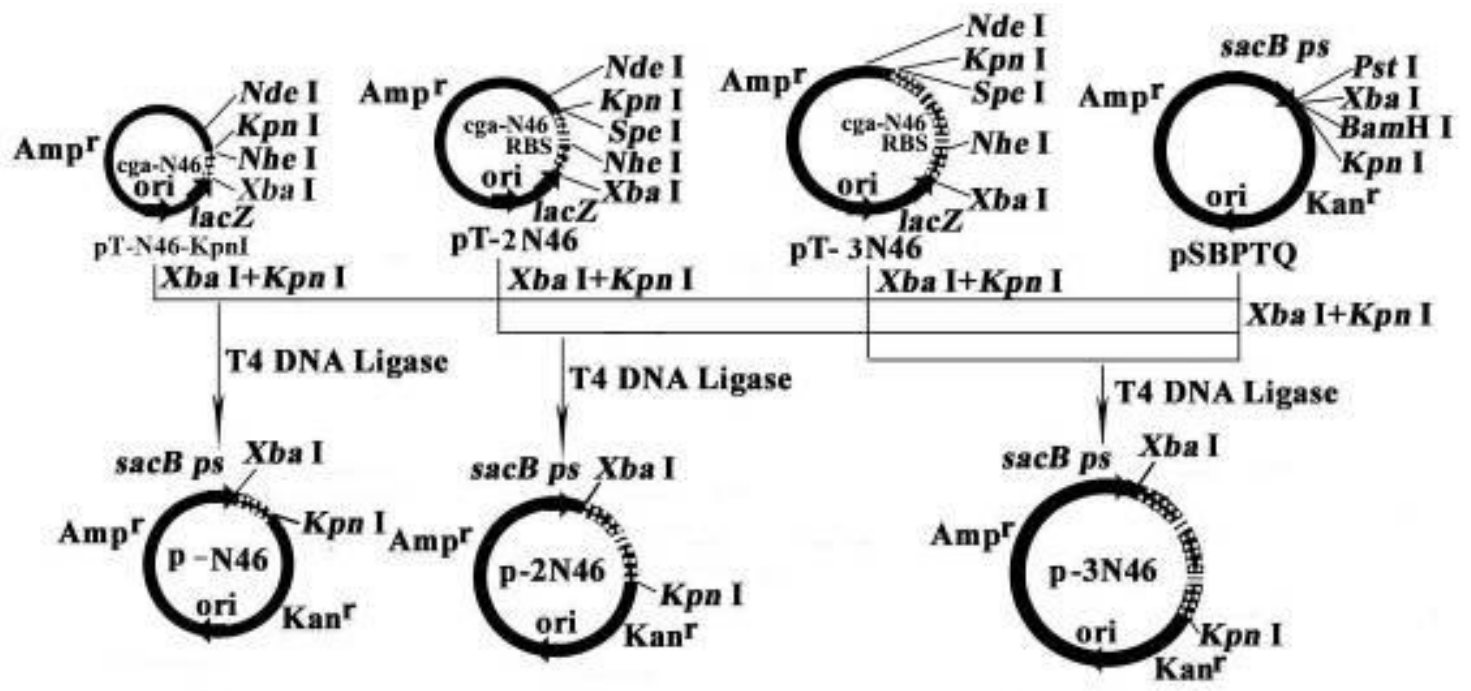

Figure 6. Construction of the recombinant pSBPTQ plasmids. Fragments from pT-N46, pT-2N46 and pT-3N46 digested with Kpnl and Xbal were linked with lining plasmid PSBPTQ digested with the same two endonucleases. The recombinant plasmids $\mathrm{p}-\mathrm{N} 46, \mathrm{p}-2 \mathrm{~N} 46$ and $\mathrm{p}-3 \mathrm{~N} 46$ were constructed.

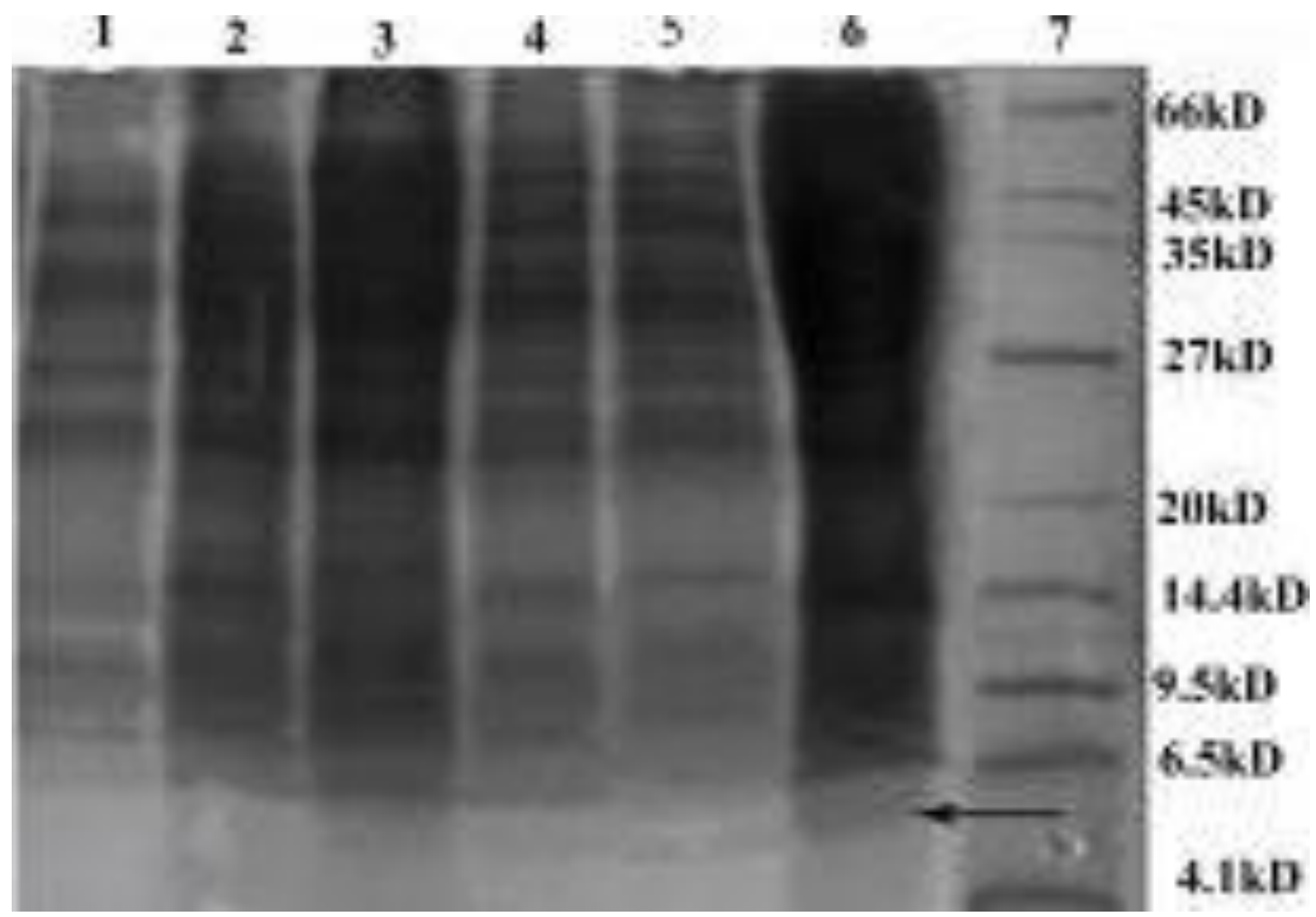

Figure 7. Expression of the cga-N46 cistronic cassettes in B. subtilis DB1342. The engineered B. subtilis cells DB1342(p-N46), DB1342(p-2N46) and DB1342(p-3N46) were cultured in $2 \times \mathrm{MSR}$ medium(5\% w/v yeast extract, $3 \% \mathrm{w} / \mathrm{v}$ peptone, $0.6 \% \mathrm{w} / \mathrm{v} \mathrm{K}_{2} \mathrm{HPO}_{4}, 0.6 \% \mathrm{w} / \mathrm{v}$ glucose) containing $10 \mu \mathrm{g} / \mathrm{ml}$ kanamycin for $3 \mathrm{~h}$. Protein expression was induced by the addition of $2 \%$ sucrose. Culture broth of each engineered strain was collected after $30 \mathrm{~h}$ and the yields of CGA-N46 in 30 $\mathrm{\mu l}$ culture broth were compared by $16.5 \%$ SDS-PAGE. Lane 1: Culture broth of DB1342(pSBPTQ). Lane 2: Sucrose-uninduced culture broth of DB1342(p-3N46). Lane 3: Sucrose-induced culture broth of DB1342(p-N46). Lane 4: Sucrose-induced culture broth of DB1342(p-2N46). Lane5-6: Sucrose-induced culture broth of DB1342(p-3N46). Lane 7: Low range protein marker. Solid arrow: CGA-N46. 


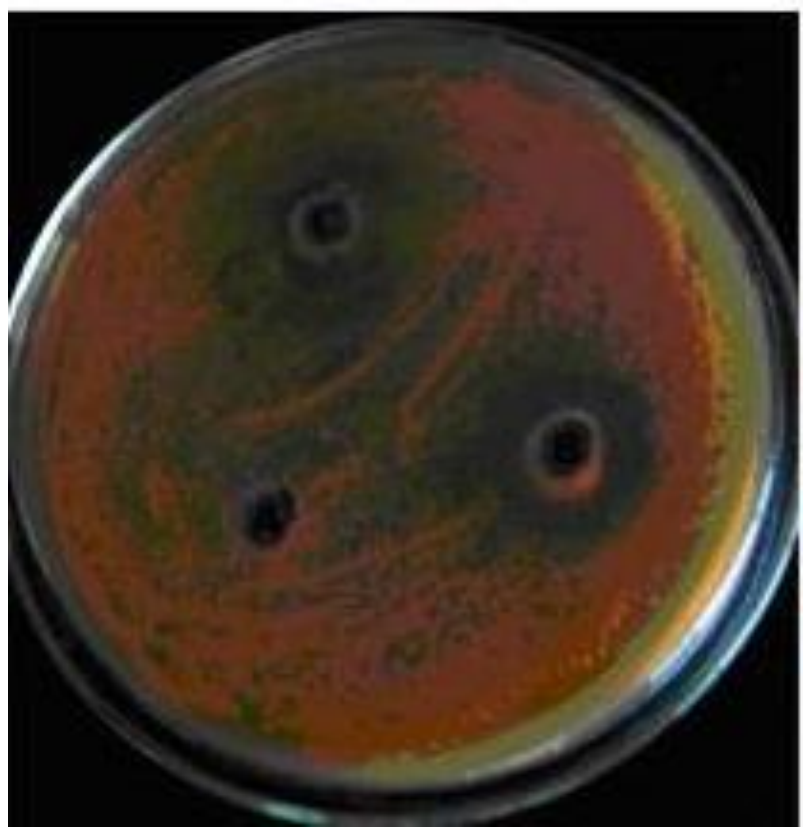

Figure 8. Antifungal activity of the filtered sucrose-induced culture broth of $B$. subtilis DB1342(p-3N46). The culture broth was filtered by $0.22 \mu \mathrm{m}$ filter paper. One hundred $\mu \mathrm{l}$ of the filtered culture broth was added into the hole of the plate. After the plates were incubated overnight, another $100 \mu \mathrm{l}$ filtered culture broth was added into the hole. After incubating for a total of $36 \mathrm{~h}$, the diameters of the clear zone were measured in millimeters. A. Culture broth of $B$. subtilis DB1342(pSBPTQ). B. Culture broth of $B$. subtilis DB1342(p-3N46). C. Culture broth of B. subtilis DB1342(pN46).

of Henan Province (112102310325) and Postgraduate Educational Innovation Foundation of Henan University of Technology (10YJS031).

\section{REFERENCES}

Aslam M, Shahid M, Rehman FU, Batool Al, Naveed NH, Sharif S, Ata A (2011). Isolation and purification of bacteriocin from $S$. thermophilus. Afr. J. Microbiol. Res. 5(18):2642-2648.

Blois A, Holmsen $\mathrm{H}$, Martino G, Corti A, Metz-Boutigue $\mathrm{M}-\mathrm{H}$, Helle KB (2006). Interactions of chromogranin A-derived vasostatins and monolayers of phosphatidylserine, phosphatidylcholine and phosphatidylethanolamine. Regul. Peptides, 134: 30 - 37.

Diekema DJ, Beekmann SE, Chapin KC, Morel KA, Munson E, Doern GV (2003). Epidemiology and outcome of nosocomial and community-onset bloodstream infection. J. Clin. Microbiol. 41: 36553660.

Foubister V (2003). Superpeptide to treat Candida albicans. Drug Discov. Today 8: 380-381.

Gudlaugsson O, Gillespie S, Lee K, Vande Berg J, Hu J, Messer S, Herwaldt L, Pfaller M, Diekema D (2003). Attributable mortality of nosocomial candidemia, revisited. Clin. Infect. Dis. 37: 1172-1177.

Hierro A, Kim J, Hurley JH (2005). Polycistronic expression and purification of the ESCRT-II endosomal trafficking complex. Meth. Enzymol. 403: 322-332.

Lee JH, Kim MS, Cho JH, Kim SC (2002). Enhanced expression of tandem multimers of the antimicrobial peptide buforin II in Escherichia coli by the DEAD-box protein and trxB mutant. Appl. Microbiol. Biotechnol. 58: 790-796.
Lennick M, Haynes JR, Shen SH (1987). High-level expression of alpha-human atrial natriuretic peptide from multiple joined genes in Escherichia coli. Gene 61: 103-112.

Li R, Zhang T, Luo J, Wang F, Gu Q, Gan J, Xiao F (2006). Antifungal activity fragments of $\mathrm{N}$ domain of chromogranin $\mathrm{A}$. Acta Scientiarum Naturalium Universitatis Sunyatseni, 45: 64-67.

Lugardon K, Chasserot-Golaz S, Kieffer AE, Maget-Dana R, Nullans G, Kieffer B, Aunis D, Metz-Boutigue M-H (2001). Structural and biological charaterization of chromofungin, the antifungal chromogranin A-(47-66)-derived peptides. J. Biol. Chem. 276: 35875 35882.

Lugardon K, Raffner R, Goumon Y, Corti A, Delmas A, Bulet P, Aunis D, Metz-Boutigue $\mathrm{M}-\mathrm{H}$ (2000). Antibacterial and antifungal activities of vasostatin-I, the $\mathrm{N}$-terminus fragment of chromogranin A. J. Biol. Chem. 275: 10745-10758.

Ortega M, Marco F, Soriano A, Almel M, Martínez JA, López J, Pitart C Mensa J (2011). Candida species bloodstream infection: epidemiology and outcome in a single institution from 1991 to 2008. J. Hosp. Infect. 77: 157-161.

Shim Y, Duan M, Chen X, Smerdon MJ, Min J (2012). Polycistronic coexpression and nondenaturing purification of histone octamers. Anal. Biochem. 427:190-192.

Spizizen J (1958). Transformation of biochemically deficient strain of Bacillus subtilis by deoxyribonucleate. Proc. Natl. Acad. Soc. USA, 44: 1072-1078.

Tan S (2005). The pST44 polycistronic expression system for producing protein complexes in Escherichia coli. Protein Expr. Purif. 40: 385395.

Wisplinghoff $\mathrm{H}$, Bischoff $\mathrm{T}$, Tallent SM, Seifert H, Wenzel RP, Edmond MB (2004). Nosocomial bloodstream infections in US hospitals: analysis of 24179 cases from a prospective nationwide surveillance study. Clin. Infect. Dis. 39: 309-317.

Wong S (1995). Advances in the use of Bacillus subtilis for the expression and secretion of heterologous proteins. Curr. Biol. 6: 517522.

Wu S, Wong S (1999). Development of improved pUB110-based vectors for expression and secretion studies in Bacillus subtilis. J. Biotechnol. 72:185-195.

Yang L, Yang T, Cheng N, Xie J, Zhang Y, Niu B (2006). A method of construction polycistron tandem gene of small peptide. China Biotechnol. 26: 45-47.

Zhong Z, Xu Z, Peng L, Huang L, Fang X, Cen P (2006). Tandem repeat mhBD2 gene enhance the soluble fusion expression of hBD2 in Escherichia coli. Appl. Microbiol. Biotechnol. 71:661-667. 